\title{
Teacher Sustenance of Emotional Balance among Children aged 4-6 with Disability in Kenya: Addressing Safety, Actualization and Independence
}

\author{
Ganira Khavugwi Lilian, Paul Amolo Odundo, Ruth Wangui Kahiga, Evanson Muriuki \\ Muriithi, John Mwangi and Julius Chemkeney Koring'ura \\ University of Nairobi, Kenya
}

\begin{abstract}
Teacher management of individual's physical and psychological wellbeing of learners tend to deliver them from pessimistic and traumatic life threatening circumstances in which children with disabilities (CWD) find themselves particularly between ages 4-6 in Early Childhood Education (E.C.E) centres. The pessimistic and traumatic episodes creates emotional imbalance in children with disabilities particularly navigating around their safety, self actualization and independence in participation in school and community-based activities. Although teachers are instrumental in developing and creating positive relationships necessary for effective participation of CWD, Safety, actualization and independence is often not addressed resulting in frustration, neglect and negative perception which lower inclusion in the learning process. This study assessed teacher sustenance of emotional balance of preschool children aged 4-6 with disability in Nairobi County, Kenya, addressing Safety, Actualization and Independence. Descriptive research design was used to gather data. Target population was 153 preschool teachers, 102 head teachers and 150 preschool with CWD. Purposive and simple random samplings were used. Analysis was obtained through editing, coding classifying and tabulation. The study found inadequacies in emotional stability of CWD. In order to mitigate inadequacies, teachers should supplement core practices with interventions such as providing culturally relevant curricular that reflects experiences for CWD to experience love, joy, acceptance and optimism, create healthy inclusive learning environments and demonstrate appropriate pedagogy for CWD as well as establish and maintain positive relationships. The study recommends the government to adhere to principles of CRPP and $C R C$, and address barriers to effective participation as well emotional adjustment of CWD.
\end{abstract}

\section{Introduction}

Feeling a sense of personal self worth stimulates learning, growth, participation as well as enhancing overall well being and quality of life for children with disabilities (CWD) to effectively participate in society. Teacher support in providing emotional balance of safety, self- actualization and independence is a major component of meeting developmental milestones for CWD to lead productive lives from childhood to maturity. By supporting emotional assurance for CWD, educationists, policy makers and governments aid in providing indispensable foundation needed for CWD to grow into prosperous productive adults. Additionally, emotional well-being of CDW is associated with higher school engagement, less troublesome behavior, enthusiasm and positive friendship. Furthermore, Boyd et al., [3] asserts that emotional balance influences decision making along with daily learning experiences for CWD. As a result, CWD who experience emotional confidence have a greater likelihood of becoming economically productive and engaged citizen equipped to fully participate in school and in society. Consequently inadequate attention to emotional stability of CWD may translate into frustration, aggression and anxiety which in turn reduce effective participation in school and in society.

In spite of potential significance of emotional stability for CWD, the Convention on the Rights of Persons with Disabilities, during United Nations Treaty Collection [5], revealed that far too often CWD are among the last in line for resource allocation and are viewed as objects for pity, discrimination and abuse. In support of this view World Health Organization [20], contends that globally people with disabilities are treated with little respect and recognition, a scenario that immensely impedes realization of effective participation as well as emotional reassurance. Further still, CWD constantly experience abuse such as (physical, emotional, sexual, violation of rights and neglect) which inhibits enjoyment of basic human rights and inclusion in society. In regard to increasing effective participation of CWD and decreasing segregation from curricular, cultures and communities, Salamanca Statement and Framework for action [19] upholds that inclusion and participation are vital to human dignity. Thus emotional stability for CWD should be addressed in an inclusive environment for effective participation to be achieved.

While the situation for CWD is changing for better, there still exist gaps in policies and planning that thwart achievement of emotional confidence as well as full participation in school and in society. Besides, Chavan et al. [4], assert that barriers in providing emotional stability are evident in both 
developed and developing countries. Drawing from this, Scheer et al. [16] maintain that in order to overcome gaps and barriers such as ignorance and prejudice surrounding disability, education and awareness is crucial for realization of effective participation for CWD. In such circumstances, unless social, cultural, attitudinal and physical barriers are eradicated then CWD will constantly lag behind in realizing emotional balance and effective participation. Based o this realization, Government of Kenya ought to act with haste to remove barriers to effective participation through addressing: policy and legislation, barriers to financing and affordability, barriers to service delivery, human resource barriers, as well as filling gaps in data and research. Additionally components of emotional assurance such as (confidence, security, stability, self-reliant self-fulfillment, autonomy, decisionmaking, goal-setting and self-management) should be addressed fully in an inclusive environment for CWD to gain self-assurance for effective participation.

In support of the rights of CWD, the Convention on the rights of persons with disabilities (CRPD) [5] and the Convention on the Rights of the Child (CRC) [6] all point towards overcoming discrimination and recognizing the right to full participation of CWD in the home, in school, in services, in recreation activities and in all aspects of life. However, in spite of the conventions, frequently CWD are excluded from participating fully in life in the society, as indicated by National Coordinating Council on Disability (NCCD), [14]. In addition CWD are not recognized along with being thought to have little contribution to the society. To this effect continuous exclusion reduces opportunities for CWD to learn, grow and develop, hence contributing to diminished probability of emotional stability and participation. Barnett et al., [1], notes that responding to emotional balance of CWD in inclusive preschools requires government responsibility to protect the rights of CWD under its jurisdiction. This entails focusing not only on disability, but on investing in removing physical, cultural, economic, cultural and communicational barriers that impede realization of emotional confidence and effective participation for CWD.

Besides, studies by Ganira et al. [8], on impact of social needs on participation of CWD, pointed out that preschool- teachers are not conversant with various needs of CWD, a scenario that encumber effective participation. In addition, diverse types of disabilities post a challenge to preschool teachers owing to insufficient training in handling needs of CWD. Given that teachers are key elements in CWDs' learning, expanding teacher training and professional development on emotional balance for CWD is vital to achieving success in effective participation as well as balanced learner needs.
Consequently, Dessemontet [7], opined that effective classroom management leads to increased academic achievement and decreased problem behaviors of learners. With this in mind, classroom management should be considered as a powerful cluster of techniques in creating meaningful learning experiences for CWD and tapping on intellectual and learner needs. It is in this context that the study assessed teacher role in emotional balance of CWD in pre-schools in Nairobi County, Kenya.

\section{Safety and participation of CWD}

Building a sense of confidence, security, and stability is a natural way of protecting CWD from harm, thus maintaining emotional balance. Besides, CWD feel safe when they know no harm will befall them whether physical, sexual, emotional, psychological abuse, or neglect. As soon as CWD are protected from any form of harm, they are likely to feel free to reach out to others and explore the environment for effective participation in schooling. According to Shutts et al. [17], every child including CWD have a right to live full productive life in an environment that builds confidence, friendship, security and happiness, irrespective of disability or background. Furthermore, Article 11 of Convention of the Right of persons with disability requires nations to ensure safety of persons with disabilities including children. While providing emotional stability is dependent on effective pre-school surroundings, a safe and secure childhood environment provides the best chance of achieving a healthy well adjusted adulthood that translates into assured participation, as highlighted by National Association for the Education of Young Children (NAEYC) [13].

\subsection{Self actualization and participation of CWD}

Development of skills and social competence is essential for the wellbeing and success for CWD to develop self-reliance, self-fulfillment, autonomy, personal growth, and personal potential in life. Every individual including CWD has a natural tendency to emotionally fulfil their potential in all aspects of life. According to Birney et al., [2], CWD are eager to undergo new experiences, learn new ideas and skills and try out new things as well as feel complete and valid in all aspects of life. In regard to this, Hewitt, [9], affirmed that self actualization is an effective concept that assists CWD in dealing with depression, low self esteem and poor life circumstances while reducing them to passive participants. Consistent with this is the reality that self-actualization helps in improving quality of life and considerably reduces risk of adverse impact of challenging life experiences for CWD, to attain emotional confidence. 


\subsection{Self independence and participation of CWD}

Leithwood and Mascall [11], Points out that when CWD share power and responsibility for decision making, effective learner participation is likely to be achieved. This entails fostering skills, knowledge and opportunities that contribute to independence to CWD such as (decision-making, goal-setting, and teaching self management skills).In support of with these, Reading et al. [15], affirmed that CWD can flourish if they are encouraged to be more independent and try out new skills which builds confidence. To this effect, teachers should provide opportunities during group work for CWD to use leadership skills in participating in a range of activities that permits discovery of new areas of interest as well as allowing CWD to speak for themselves rather than someone else representing. Further still, analysis by Sinclair [18], showed that CWD require opportunities in making autonomous decisions, be involved in decision making and be listened to by adults and peers to assure confidence, build self esteem and achieve emotional stability. In order to achieve this, teachers, should provide guidance to sensitize communities on independence for CWD to realize emotional balance at school and at home. While children are increasingly involved in decision making, growth has been slow in respect to involving CWD who are inadequately involved and challenged to participate in social activities, (Sinclair) [18].

\section{Statement of the problem}

The CWD are among the last in line for resource allocation and viewed as objects for pity, discrimination and abuse, lowering self esteem and emotionally disparaging them. The WHO [20], indicates that globally people with disabilities are treated with little respect and recognition inhibiting enjoyment of basic human rights in addition to destroying them emotionally. Furthermore, emotional competences for CWD are not recognized along with CWD being thought to have little contribution to the society further lowering the desire to realize sustained emotional growth. More still, gaps in policies and planning delay provision of essential emotional stability to CWD. Sadly, Chavan et al. [4], observed that barriers in providing emotional assurance is evident in both developed and developing countries; where abuses, derogatory remarks and limited attention reduce them to social misfits lowering their ability to adjust to the demands of schooling and community learning. Regardless of CRPD and CRC emphasizing equality frequently CWD are excluded from participating fully in life in the society as indicated by National Coordinating Council on Disability (NCCD) [14]. Based on this, the study assessed teacher role in emotional balance of children aged 4-6 with disability in Nairobi County addressing safety, actualization and independence.

\section{Purpose and objectives}

The purpose of this study was to examine teacher role in emotional balance of pre-school children in Nairobi County. The exercise was intended to provide useful information that could facilitate improvement of pre-schools' management of emotional stability and participation of CWD. The objective of the study was to examine teacher role in emotional stability and participation of CWD in school and in society. The study purposefully raises awareness to the Ministry of Education, and the entire society on the significance of emotional adjustment for CWD.

\section{Theoretical framework}

The study adopted the theory of Abraham Maslow's hierarchy of needs [12], which emphasized that most needs are emotional. In hierarchy of needs, physical needs are at the bottom implying that once these needs are met, emotional assurance become most significant and achievable. However, in instances where CWD experience emotional imbalance, frustration and anxiety yields. When CWD experience emotional stability, fewer problems are encountered in learning at all levels. To this effect, attention to emotional stability may well predispose CWD to increased levels of participation, improved confidence and stability. Accordingly, emotional reassurance should be delivered in an environment respectful of cultural protection and participation rights of CWD in school and at home. Skills such as; confidence, security, stability, selfreliance, self-fulfillment, autonomy, decision making, goal setting and self-management are integral to achieving emotional balance and effective participation.

\section{Conceptual framework}

A conceptual framework details possible outcomes of action to represent preferred approach to an idea by explaining teacher's role in emotional balance and participation of CWD in school. Since emotional stability determines physical and psychological well being of CWD, safety, actualization and independence are vital in participation and realizing emotional assurance in the learning process. The CWD need an inclusive environment which advocates for confidence, security, stability, self-reliance, self-fulfillment, autonomy decision making goal-setting and self - 
management in order to achieve inclusion and emotional reassurance in school and in community.

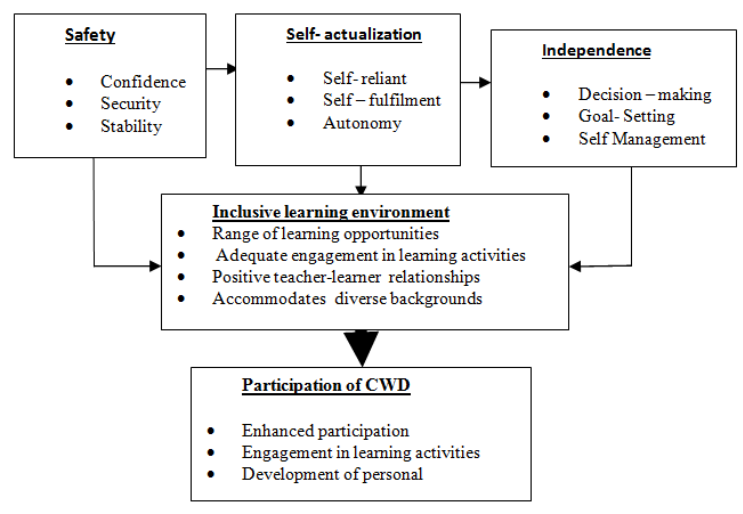

Figure 1. Conceptual frame work

\section{Data and Methodology}

This study employed a descriptive research design to gather data. Simple random sampling technique was used to identify 150 pre-schools. Purposive sampling and simple random sampling were then used to obtain a target population of 102 head teachers, 153 pre-school teachers and 150 preschool CWD aged 4-6. Instruments for this study were questionnaires, interview schedules and observation guide. A questionnaire was administered to teachers and it dealt with teachers' familiarity with emotional balance of CWD. An interview schedule was used to obtain information from head teachers on views concerning emotional balance for CWD. Further still, Interview schedule was used on CWD to obtain views on emotional stability. According to Jackson [10], descriptive research design is commonly represented by use of frequency charts, bar graphs and pie charts to tabulate the information gathered appropriately. Data collection for this study was obtained through editing, coding and tabulation procedures.

Table 1. Years of Service and Academic Qualification of the Respondents

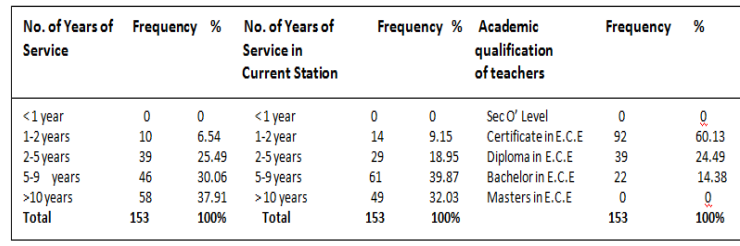

\section{Study findings}

The study sought to examine academic qualifications of Pre- school teachers From Table 1, Cumulatively $10(6.54 \%)$ out of 153 Pre- school teachers had between 1-2 years of experience, 39 (25.49\%) had between 2-5 years of experience, $46(30.06 \%)$ had between 5-9 years for experience while majority $58(37.91 \%$ ) had more than 10 years for experience signifying that they were well trained and equipped with prerequisite knowledge that enabled them to handle CWD. Additionally out of 153 teachers $14(9.15 \%)$ had taught for between 1-2 years in same station, 29(18.95\%) had taught between 2-5 years in the same station, majority $61(39.87 \%)$ had taught between 5-9 years in the same station while $49(30.03 \%)$ had taught over 10 years in the same station. These findings indicate that majority of the teachers having taught in the same station had acquired much experience in handling CWD. More findings revealed that 92(60.13\%) of the teachers had Certificate in E.C.E, 39(24.49\%) had Diploma in E.C.E, 22(14.38\%) had Bachelors degree in E.C.E. and none with masters in E.C.E. This depict that all the 153 teachers had training in E.C.E a prerequisite for providing emotional balance for CWD. Thus, expanding staff training and professional development opportunity on emotional balance of CWD is essential in learner participation. Similarly, educational and professional qualification is an essential aspect towards providing emotional confidence to CWD.

Table 2. Teacher's familiarity with emotional needs of CWD

\begin{tabular}{|c|c|c|c|c|}
\hline \multirow[b]{2}{*}{ Item } & \multicolumn{4}{|c|}{ Views } \\
\hline & $\begin{array}{l}\text { Yes } \\
\text { Frequency }\end{array}$ & $\%$ & $\begin{array}{l}\text { No } \\
\text { frequency }\end{array}$ & $\%$ \\
\hline \multicolumn{5}{|l|}{ Safety } \\
\hline The CWD are confident & 55 & 35.94 & 98 & 64.05 \\
\hline The CWD require security & 150 & 98.03 & 3 & 1.96 \\
\hline The CWD are emotionally stable & 60 & 39.86 & 92 & 60.13 \\
\hline \multicolumn{5}{|l|}{ Self actualization } \\
\hline \multicolumn{5}{|l|}{$\begin{array}{l}\text { I offer tips for CWD to be self } \\
\text { reliant. }\end{array}$} \\
\hline \multicolumn{5}{|l|}{$\begin{array}{l}\text { The CWD require self- fulfilment } \\
\text { skills }\end{array}$} \\
\hline \multirow{3}{*}{\multicolumn{5}{|c|}{$\begin{array}{l}\text { The CWD are Autonomous } \\
\text { Self independence } \\
\text { The CWD should make own } \\
\text { decisions. }\end{array}$}} \\
\hline & & & & \\
\hline & & & & \\
\hline \multirow{3}{*}{$\begin{array}{l}\text { The CWD should set own goals. } \\
\text { The CWD should have self } \\
\text { management skills }\end{array}$} & 133 & 86.92 & 11 & 7.18 \\
\hline & 147 & 96.07 & 6 & 3.92 \\
\hline & 151 & 98.69 & 2 & 1.30 \\
\hline
\end{tabular}

The study sought to examine teacher's familiarity with emotional balance of CWD. From Table 2, the study found that 55 (35.94) out of 153 teachers reported that CWD have confidence especially in handling dangerous situations, such forms of abuse suggesting adequacy in emotion balance, while 98 (64.05) did not, implying presence of emotional imbalances. This depicts that majority of teachers are not dedicated to providing safety 
needs of CWD, a situation that is likely to expose CWD to insecurity and emotional imbalance. Besides, CWD feel safe when no harm befalls them, an indication of emotional stability. Similarly 150 (98.03) discouraged teasing and bullying for CWD to develop emotional re-assurance, while 3 (1.96) did not due to ignorance of emotional security for CWD. The three teachers lamented that CWD should be treated like the rest of the children in class. Additionally, 61 (39.86) had constant routine for CWD to gain emotional stability necessary for learner participation while 92 (60.13) did not, due to inadequate knowledge on emotional balance for CWD. In one incident a teacher lamented.................These CWD overcompensate for their own insecurities by aggressiveness, I don't allow anyone to get away with these behaviours. Do not expect me to concentrate on a few CWD when I have such a large class. These findings suggest that most teachers jeopardize potential success for CWD to achieve emotional stability by failing to provide skills necessary for CWD to acquire emotional assurance.

Findings revealed that, 142 (92.81) teachers offered CWD tips for self reliance such as allowing CWD to make choices and solving own problems, however 11 (7.18) did not. Additionally, 149 (97.38) paired CWD with peers without disability for realization of self fulfilment and emotional encouragement while 4 (2.61) did not. More findings revealed that 87 (56.86) assisted CWD to understand and face consequences for behaviour to achieve autonomy and emotional adjustment, while 66 (43.13) did not, indicating lapse in emotional adjustment. Thus, focusing on improving CWD's ability to self-actualization is the best way in treating personality disorders and achieving emotional balance.

Further findings indicated that, 133 (86.92) teachers allowed CWD to make own decisions while 20 (13.07) did not hence, increasing emotional imbalance for CWD. Similar findings by Sinclair, [18], points out that when CWD share power and responsibility for decision making effective learner participation is likely to be realized, which in turn leads to emotional stability. Further still, 147 (96.07) teachers gave CWD opportunities to set own goals, suggesting emotional confidence. However 6 (3.92) did not, implying emotional instability. Finally 151 (98.69) permitted enough time for CWD to complete classroom tasks for achievement of emotional assurance while 2 (1.30) did not, even though Reading et al.[15], confirmed that CWD can flourish if they are encouraged to be more independent and try out new things for emotional balance to be realized. These findings indicate that most teachers initiated independent skills to CWD a requirement for emotional reassurance.
Table 3. Head teacher's level of understanding emotional stability for CWD

\begin{tabular}{|c|c|c|c|c|}
\hline \multirow[b]{2}{*}{ Item } & \multicolumn{4}{|c|}{ Views } \\
\hline & $\begin{array}{l}\text { Yes } \\
\text { Frequency }\end{array}$ & $\%$ & $\begin{array}{l}\text { No } \\
\text { frequency }\end{array}$ & $\%$ \\
\hline \multicolumn{5}{|l|}{ Safety } \\
\hline $\begin{array}{l}\text { The CWD have confidence in the } \\
\text { school. }\end{array}$ & 3 & 2 & 147 & 98 \\
\hline $\begin{array}{l}\text { The school offers adequate security } \\
\text { for CWD. }\end{array}$ & 26 & 17.33 & 124 & 82.66 \\
\hline $\begin{array}{l}\text { There is adequate stability for CWD } \\
\text { in school. }\end{array}$ & 12 & 8 & 138 & 92 \\
\hline \multicolumn{5}{|l|}{ Self actualization } \\
\hline $\begin{array}{l}\text { The school offers self reliant skills to } \\
\text { CWD }\end{array}$ & 137 & 91.33 & 13 & 8.67 \\
\hline $\begin{array}{l}\text { The school offers self-fulfilment } \\
\text { skills to CWD }\end{array}$ & 21 & 14 & 129 & 86 \\
\hline $\begin{array}{l}\text { The school offers autonomy skills to } \\
\text { CWD }\end{array}$ & 19 & 12.67 & 131 & 87.33 \\
\hline \multicolumn{5}{|l|}{ Self independence } \\
\hline $\begin{array}{l}\text { The school involves CWD in decision } \\
\text { making. }\end{array}$ & 139 & 92.67 & 11 & 7.33 \\
\hline $\begin{array}{l}\text { The school allows CWD to set their } \\
\text { own goals. }\end{array}$ & 123 & 82 & 11 & 18 \\
\hline $\begin{array}{l}\text { Self-management skills are taught in } \\
\text { school. }\end{array}$ & 109 & 72.67 & 41 & 27.33 \\
\hline
\end{tabular}

The study sought to find out head teacher's level of understanding of emotional balance of CWD. Findings from Table 3 revealed that, cumulatively 3 (2\%) out of 150 head teachers had training on safety needs and first aid, while 147 (98\%) did not, signifying that safety needs were not given priority by the head teachers therefore diminishing emotional stability for CWD. Further findings showed that 26 $(17.33 \%)$ reported schools having safe and enclosed outdoor areas for pre-school children implying emotional confidence while $124(82.66 \%)$ did not. Inadequate safety reduces CWDs' functioning significantly, implying emotional instability. More findings revealed that $12(8 \%)$ had provision for nap schedules during afternoon for emotional adjustment while 138 (92\%) did not, suggesting that CWD experienced emotional imbalance. When asked about inadequate safety of CWD, one head teacher lamented............... I want to prioritize supporting safety needs of CWD but do I use money designated for other children to support CWD? There is no extra funding for inclusive schools. No resources are allocated for CWD yet parents have refused to support schools financially. Based on findings head teachers should have a strong policy supporting staff in providing emotional security for CWD.

Other findings revealed that $137(91.33 \%)$ head teachers reported having supported CWD's self reliance by allowing CWD to make choices, solve problems, complete tasks successfully and rotating chores daily and weekly. Conversely $13(8.67 \%)$ did not, implying reduced emotional adjustment. Similarly, 21 (14\%) reported having enhanced self 
fulfilment skills for CWD such as accepting own talents, strengths and limitations while 129 (86\%) did not, owing to inadequate skills in emotional balance. However learner centred pedagogy raises self-actualization, a pre-requisite for emotional security. Furthermore, 19 (12.67\%) confirmed having professional training in enhancing autonomy in CDW, while $131(87.33 \%)$ did not, demonstrating emotional imbalance for CWD. Thus expanding staff training and professional development opportunities on emotional confidence for CWD is essential for learner participation.

In addition, 139 (92.67\%) reported having provided opportunities for decision making, however $11(7.33 \%)$ did not, advocating for emotional insecurity for CWD. More still 123(82\%) allowed CWD to participate in co-curriculum activities such as music and drama for emotional stability, while $27(18 \%)$ did not, pointing to inadequacy in emotional security for CWD. Additionally, 107(77.67) stated that CWD are capable of making own decisions in daily school activities such as types of clubs to join, while 41 (27.33\%) did not, denoting emotional imbalance and reduced learner participation.

Table 4. Children with disabilities view on emotional stability

\begin{tabular}{|c|c|c|c|c|}
\hline \multirow[b]{2}{*}{ Item } & \multicolumn{4}{|c|}{ Views } \\
\hline & $\begin{array}{c}\text { Yes } \\
\text { Frequency }\end{array}$ & $\%$ & $\begin{array}{l}\text { No } \\
\text { Frequency }\end{array}$ & $\%$ \\
\hline \multicolumn{5}{|l|}{ Safety } \\
\hline $\begin{array}{l}\text { Am confident in } \\
\text { crossing the road }\end{array}$ & 142 & 94.67 & 8 & 5.33 \\
\hline $\begin{array}{l}\text { I experience adequate } \\
\text { security }\end{array}$ & 92 & 61.33 & 58 & 38.67 \\
\hline $\begin{array}{l}\text { The school offers } \\
\text { adequate stability }\end{array}$ & 129 & 86 & 21 & 14 \\
\hline Self actualization & & & & \\
\hline $\begin{array}{l}\text { The school offers self } \\
\text { reliant skills }\end{array}$ & 102 & 68 & 48 & 32 \\
\hline $\begin{array}{l}\text { Self fulfilment skills } \\
\text { are evident in school }\end{array}$ & 140 & 93.33 & 10 & 6.67 \\
\hline $\begin{array}{l}\text { The school offers } \\
\text { autonomy skills }\end{array}$ & 99 & 66 & 51 & 34 \\
\hline Self independence & & & & \\
\hline $\begin{array}{l}\text { I am involved in } \\
\text { decision making }\end{array}$ & 126 & 84 & 24 & 16 \\
\hline $\begin{array}{l}\text { I am able to set my } \\
\text { own goals }\end{array}$ & 113 & 75.33 & 37 & 24.67 \\
\hline $\begin{array}{l}\text { The school offers self } \\
\text { management skills }\end{array}$ & 89 & 59.33 & 61 & 40.67 \\
\hline
\end{tabular}

The study examined CWD's understanding of emotional stability. Findings from Table 4 illustrates $142(94.67 \%)$ out of 150 CWD reported having confidence in crossing busy roads, denoting emotional security while 8 $(5.33 \%)$ did not due to fear, suggesting emotional imbalance. Further, 92 (61.33) reported having adequate security in school, while 58 (38.67), did not, meaning emotional insecurity. Additionally, inadequate stability was reported by $129(86 \%)$ due to teasing and bulling in school while $21(14 \%)$ did not; suggesting that safety needs for CWD was not a major concern in many schools, hence emotional imbalance and reduced participation. However, in an environment where autonomy, hope, and confidence prevail, CWDs' are likely to transform into effective participants, a requirement for emotional assurance.

Additional findings revealed that, 102(68\%) were self-reliant in competing daily school tasks successfully, symbolizing emotional assurance, while $48(32 \%)$ were not. More findings revealed that 140(93.33) were taught self-fulfillment skills such as acting responsibly, attending to new challenges, and setting realistic goals, while 10(6.67) were not, resulting into emotional imbalance. Finds on autonomy revealed that, 99(66\%) CWD were good at self-feeding, independent dressing and grooming, hygiene and toileting as well as helping with daily chores, resulting in emotional confidence, while 51(34\%) were not, denoting emotional instability. Equally important, CWD who experience supportive and long lasting relationships tend to feel more independent and connected. In consequence emotional re-assurance is achieved.

In addition $126(84 \%)$ reported having made own decisions for example classroom rules, solving own problems, in addition to choosing co-curriculum activities, therefore enhancing emotional confidence, while 24(16\%) did not due to inadequate confidence. More still 113(75.33\%) CWD were involved in goal setting for instance selecting own learning materials, recognizing own talents and interests, sharing own experiences while $37(24.67)$ did not, due to inadequate skills, resulting in emotional instability. More still 89(59.33\%) CWD managed their own life through self-control, exhibiting confidence, good time management and managing anger, demonstrating emotional adjustment while 61(40.67\%) did not due to laxity in teachers recognizing and understanding the need for emotional balance. Though CWD experienced self-independence, safety and selfactualization was inadequate lowering the attainment of emotional assurance and effective participation.

\section{Conclusions}

The findings highlight the significance of teacher role in emotional balance of CWD. The CWD ability to learn and function as contributing members of society rests entirely on safety, self- 
actualization and independence. Understanding of emotional balance enables CWD meet demands of everyday life, lower destructive behaviour, cope with stress as well as focus on personal growth to live more authentically. Teachers' pursuing emotional stability permit CWD in experiencing healing from stress anxiety, depression and transform into helpful patterns of thinking, feeling as well as gain confidence in life. Given daily stressors faced by CWD, promoting emotional stability is likely to build positive relationships, promote pro -social behaviour, academic success and effective participation in class and in society. If school learning environments are improved to support inclusion and emotional balance, CWD are likely to experience connection to school and reduced emotional distress.

The study found inadequacies in identifying and providing emotional stability to CWD. Irrespective of disability, CWD have skills that can be developed for realization of effective participation only if emotional competences of safety, actualization and independence are accorded in the correct manner. Implication of this evidence is that supporting teachers in developing emotional balance for CWD should be the major focus of Early Childhood intervention services. To achieve this, Early Childhood interventions need well developed skills in engaging and building partnership with parents as well as knowledge of strategies and programs for building positive relationships with CWD as well as promoting emotional well being of CWD in school and in society. Thus, classroom management should be improved as teachers learn to regulate emotional balance for CWD.

\section{Recommendations}

These recommendations derive from the study findings and they include some of the suggestions put forward by the respondents.

- Teachers should focus on programmes that anchor on skill development such as technology enthusiast, innovativeness, commitment, preparation tolerance and strategies such as; daily schedule for CWD, an orderly classroom management, respect for CWD, and clear open communication between learner and teacher, consistent with emotional stability of CWD, as well as link to community recourses beyond school.

- Teachers should supplement core practices with interventions such as providing culturally relevant curricular that reflects experiences for CWD to experience love, joy, acceptance and optimism. This should include demonstrating appropriate pedagogy, caring, and concern for CWD and establishing and maintaining positive relationships with CWD.

- Teachers should implement school programs and approaches for creating healthy inclusive learning environments that promote emotional stability through comprehensive educational and professional development emphasizing importance of emotional reassurance for CWD.

- The Government of Kenya should align its policies and programs with those of CRPD and $\mathrm{CRC}$ in order to enhance equal opportunities for effective participation. This will carter for special needs of CWD in education as well as equal access to education and facilities that are integrated into society to the extent compatible with emotional security of CWD.

- Education laws in Kenya should be monitored to identify features that limit CWD from enjoying equal educational opportunities. Distribution of resources should promote synchronization of efforts in meeting emotional demands of CWD in inclusive environments, hence, avoiding escalation of emotional imbalances. Other key players such as local authorities, parents and communities also should take up responsibilities of meeting emotional security of CWD.

- The Ministry of education should ensure that policies, structures and processes are inclusive both in philosophy and practice, since insufficient understanding, data and information about disability impacts negatively on participation, creating emotional imbalances to CWD. To ensure visibility of all groups of CWD in relation to attendance, completion and attainment in education it is vital that data are disaggregated by disability, economic status, and geographical status to promote harmony in addressing emotional needs of CWD.

- To date there has not been extensive studies on emotional needs of children with disabilities. Most studies focus on reducing disability and treatment. Based on the experiences of this study, the researcher recommends need for more research on emotional balance of children with disabilities. An inclusive intervention program should address discrepancies in the area of emotional security of children with disabilities. Thus future studies should explore ways of making emotional awareness and mindfulness to supporting well being of CWD. 


\section{References}

[1] Book (Authored): Barnett, W.S., Carolan, M.E., Squires, J.H., Clarke Brown, K., \& Horowitz, M. (2015). The state of preschool 2014: State preschool yearbook. New Brunswick, NJ: National Institute for Early Education Research.

[2] Journal Article: Birney, D., Fogarty, G.,\& Plank, A. (2005). Assessing schematic knowledge of introductory probability theory. Instructional Science, $33,341-366$

[3] Boyd, J., Barnett, W. S., Bodrova, E., Leong, D. J., \& Gomby, D. (2005). Promoting children's social and emotional development through preschool. New Brunswick, NJ: NIEER.

[4] Chavan, M., Yoshikawa, H., \& Bahadur, C. (2013).The Future of Our Children: Lifelong, Multi generational Learning for Sustainable Development. (Report of the thematic workgroup on early childhood development, education and the transition to work of the U.N. sustainable development solutions network). New York, Paris, and New Delhi: U.N. Sustainable Development Solutions Network.

[5] Convention on Rights of People with Disabilities (2006). Official Statement of the UN Secretary General, SG/S M/10797. Available at: http://www.un.org/News/Press/ docs/2006/sgsm10797.doc.htm

[6] Convention on the Rights of the Child, (1989). Promotion and protection of human rights: implementation of human rights instruments. Torture and other cruel, inhuman or degrading treatment or punishment: Note by the Secretary General, U.N. G.A.O.R. 63 Sess., Item 67(a)

[7] Journal Article: Dessemontet, R.S., Bless, G. \& Morin, D. (2012). Effects of inclusion on the academic achievement and adaptive behavior of children with intellectual disabilities. Journal of Intellectual Disability Research, 56 (6), 579587

[8] Journal Article: Ganira, K. L., Odundo,P.A., Ngaruiya,B., Obae, N.R. (2015). Impact of Social Needs on Participation of Children Aged 4-6 with Disabilities in Early Childhood Education Classes in Starehe Division in Nairobi County, Kenya. International Journal of Elementary Education. Vol.4, No.2, 2015, pp. 25-34. doi: 10.11648/j.ijeedu.

20150402.12

[9] Journal Article: Hewitt, John P. (2009). Oxford Handbook of Positive Psychology. Oxford University Press. pp. 217-224. ISBN 978-0-19-518724-3

[10] Book (Edited): Jackson,S. L.(2009). Research Methods And Statistics: A Critical Thinking Approach (3rd edition). Belmont, CA: Wadsworth.

[11] Journal Article: Leithwood, K, Mascall, B.( 2008). Linking leadership to student learning: The contributions of leader efficacy. Educational Administration Quarterly, 44: 496-528

[12] Book (Authored): Maslow, A, (1998). Towards a psychology of being (3rd ed.) New York: Wiley \& Sons.

[13] National Association for the Education of Young Children (NAEYC), (2002). and National Association of Early Childhood Specialists in State Departments of Education. Early Learning Standards: Creating the Conditions For Success. Washington, DC: National Association for the Education of Young Children.

[14] NCCD, (2005). Biwako Millennium Framework for Action Towards an Inclusive Barrier Free and Rights Based Society for Persons with Disabilities, Hanoi, Labour and Society Publishing House

[15] Reading, J., Kmetic, A., \& Gideon, V. (2007). First Nations Wholistic policy and planning model. AFN Discussion Paper for WHO Comission on Social Determinants of Health. Retrieved from:

http://www.fsin.com/healthandsocial/childportal/detail. php?firstLevel $=\&$ s eco ndLevel $=\&$ currentItemId $=177$

[16] Journal Article: Scheer, J.M., Kroll, T, Neri, M.T, Beatty P. (2003). Access barriers for persons with disabilities: the consu- mers perspective. Journal of Disability Policy Studies, 13:221-230.doi:10.1177/ 104420730301300404

[17] Journal Article: Shutts, K., Roben, C. K. P., \& Spelke, E. S. (2013). Children's use of social categories in thinking about people and social relationships. Journal of Cognition and Development, $14,35-62$.

[18] Journal Article: Sinclair, R. (2004). Participation in Practice: Making it Meaningful, Effective and Sustainable', Children and Society, 18, pp. 106-118.

[19] The Salamanca statement and framework for action on special needs educational. Salamanca UNESCO (1994): UNESCO.

[20] World Health Organization (2011) .World Report on Disability. Geneva: WHO/World Bank. http://www.who.int/disabilities/world_report/2011/en/i ndex.html; 